\title{
PERAN BRAND IMAGE MEMEDIASI PENGARUH CELEBRITY ENDORSER TERHADAP PURCHASE INTENTION
}

\author{
Putu Agung Aprilia Roshan' \\ Ida Bagus Sudiksa ${ }^{2}$ \\ ${ }^{1,2}$ Fakultas Ekonomi dan Bisnis Universitas Udayana (Unud), Bali, Indonesia \\ email:apriliaroshan25@gmail.com
}

\begin{abstract}
ABSTRAK
Tujuan dari penelitian ini adalah untuk mengetahui peran brand image memediasi pengaruh celebrity endorser terhadap purchase intention pada calon konsumen produk lipstik Wardah. Penelitian ini dilakukan di Kota Denpasar, dengan menggunakan ukuran sampel sebanyak 108 responden dengan metode purposive sampling. Adapun teknik analisis data yang digunakan dalam penelitian ini yaitu Analisis Jalur (Path Analysis) dan disertai dengan Uji Sobel untuk menguji hipotesis yang diajukan. Hasil data responden secara langsung dapat dilihat yaitu celebrity endorser berpengaruh positif dan signifikan terhadap brand image; brand image berpengaruh positif dan signifikan terhadap purchase intention; celebrity endorser berpengaruh positif dan signifikan terhadap purchase intention; serta brand image secara signifikan mampu memediasi celebrity endorser terhadap purchase intention.
\end{abstract}

Kata Kunci : celebrity endorser, brand image, purchase intention

\begin{abstract}
The purpose of this research is to know the role of brand image mediate the influence of celebrity endorser against purchase intention on a prospective consumer products lipstick Wardah. This research was conducted in Denpasar city, using a sample size as much as 108 respondents with a purposive sampling method. As for the data analysis technique used in this study is Path Analysis and accompanied by Sobel test to test the hypothesis put forward. Based on the results of research conducted, the brand image was able to mediate the celebrity endorser against purchase intention. Data of respondents are directly viewable is celebrity endorser of the positive and significant effect against brand Image; brand image is positive and significant effect against purchase intention; celebrity endorser of the positive and significant effect against purchase intention; as well as brand image are significantly able to mediate the celebrity endorser against purchase intention.

Key Word: celebrity endorser, brand image, purchase intention
\end{abstract}




\section{PENDAHULUAN}

Perdagangan bebas kini terlihat dengan meluasnya pasar produk jasa atau barang yang mengakibatkan ketatnya persaingan antara perusahan. Timbulnya persaingan tersebut perusahaan kian berkompetisi untuk mengembangkan produknya melalui teknologi yang efektif dan efisien. Kemajuan dan teknologi yang semakin berkembang merupakan salah satu penyebab adanya persaingan antar perusahaan.

Perusahaan menciptakan suatu produk untuk memenuhi kebutuhan konsumen yang semakin berkembang dalam hal kualitas serta kuantitas. Perkembangan pasar yang semakin meningkat membuat permintaan produk yang diinginkan oleh konsumen juga semakin meningkat. Tingginya permintaan konsumen pada suatu produk, membuat perusahaan dituntut untuk tetap kompetitif dalam menciptakan produk agar dapat mempertahankan konsumennya. Salah satu persaingan pasar yang berkembang di Indonesia adalah bisnis kosmetik. Persaingan bisnis kosmetik semakin ketat dengan munculnya merek luar yang masuk ke dalam pasar kosmetik di Indonesia. Salah satu kosmetik yang paling banyak dibutuhkan wanita jika ingin tampil cantik dalam sekejap adalah lipstik (Anindyakirana, 2016).

Lipstik adalah produk kosmetik esensial yang diperlukan setiap perempuan. Produk ini mudah diaplikasikan serta efek yang dihasilkan melalui polesannya dapat mengubah penampilan agar lebih baik. Lipstik memiliki pilihan warna yang tidak terbatas, warna hitam sampai warna "ajaib" seperti hologram serta metalik (Marcinda,2017). Seiring dengan berkembangnya waktu lipstik mulai mengalami perkembangan mulai dari jenis, bentuk, dan warna. Adanya perkembangan tersebut membuat lipstik diminati para perempuan dari berbagai usia.

Purchase intention (niat beli) adalah sikap konsumen dalam membuat keputusan pembelian yang akan dilakukan (Fure, 2013). Keputusan dalam pembelian produk bermerek yang dilakukan konsumen memiliki alasan tertentu. Perilaku individu diprediksi dengan niat beli dan hal penting dalam niat adalah intensitasnya (Wuryandari, 2014). Timbulnya niat beli terhadap calon konsumen pada sebuah produk diakibatkan oleh pengaruh dari produk itu sendiri. Perusahaan harus berupaya menjaga purchase intention (niat beli) konsumen agar tertarik untuk membeli produk yang dijual oleh perusahaan, calon konsumen akan membeli produk tersebut karena beberapa hal yaitu brand image dari produk tersebut.

Pandangan terhadap suatu merek yang dibentuk dari informasi serta pengalaman masa lalu terhadap merek tersebut dikatakan sebagai Brand Image. Citra konsumen yang positif pada suatu merek, lebih memungkinkan dalam melakukan pembelian (Herliza dan Saputri, 2016). Citra merek dikatakan sebagai penglihatan serta kepercayaan yang terpendam di dalam benak konsumen, sebagai cerminan asosiasi yang tertahan dalam ingatan konsumen (Kotler, 2006:266). Untuk menambah citra positif dari suatu produk, biasanya perusahaan menggunakan celebrity endorser dalam memperkenalkan atau mempromosikan produknya. 
Celebrity endorser adalah tokoh atau publik figur yang secara luas digunakan pada berbagai media untuk mendukung dan mempromosikan suatu produk (Pracista dan Rahanatha, 2014). Di era persaingan yang ketat ini, di mana menangkap posisi di ruang pikiran konsumen sangat sulit, dukungan selebritas memberi keunggulan tambahan bagi perusahaan karena memegang perhatian pemirsa. Celebrity dapat mengakalisasi penerimaan merek dan menyediakan momentum besar yang dibutuhkan merek dengan mendukung nilai intrinsik merek (Kaur dan Garg, 2016). Konsep celebrity endorsement diterapkan pada tahun 1893 dengan dukungan sabun pir oleh Lillie Langtry. Perusahaan memiliki kemampuan untuk mencapai tujuan melalui iklandalam meningkatkan penjualan produk dan pelayanan mereka melalui promosi serta iklan (Diehl dan Terlutter,2006). Celebrity adalah platform yang meyakinkan sikap konsumen terhadap merek (Ashfaq \& Ali, 2017). Dengan adanya bantuan dari celebrity endorser maka dapat membantu memperkuat ingatan konsumen terkait dari brand image suatu produk.

Penelitian yang dilakukan oleh Dei dan Sukaatmadja (2015) serta Hansudoh (2012) mengemukakan celebrity endorser berpengaruh positif serta signifikan terhadap brand image. Hasil yang bertolak belakang ditemukan oleh Nuryanti dan Haryanto (2010) yang menyatakan celebrity endorser tidak memiliki pengaruh positif dan signifikan terhadap brand image.

Salah satu lipstik yang mempunyai brand image cukup kuat dibenak konsumen adalah Wardah. Lipstik Wardah sebagai salah satu kosmetik yang mempelopori brand image dengan kualitas yang baik pada produknya. Lipstik Wardah melakukan inovasi dengan brand image-nya untuk menimbulkan pandangan bahwa kosmetik khususnya lipstik adalah merupakan kebutuhan dan lipstik Wardah dapat digunakan semua konsumen perempuan yang menginginkan tampil cantik. Terbukti pada tahun 2016 hingga sekarang lipstik Wardah berhasil menjadi produk yang mendapat Top Brand Award dalam kategorinya.

Tabel 1.

Perkembangan Top Brand Index Produk Kosmetik (Lipstik) Tahun 2012-2018

\begin{tabular}{lccccccc}
\hline $\begin{array}{c}\text { Nama Merek } \\
\text { (Produk Lisptik) }\end{array}$ & $\mathbf{2 0 1 2}$ & $\mathbf{2 0 1 3}$ & $\mathbf{2 0 1 4}$ & $\begin{array}{c}\text { TBI (\%) } \\
\mathbf{2 0 1 5}\end{array}$ & $\mathbf{2 0 1 6}$ & $\mathbf{2 0 1 7}$ & $\mathbf{2 0 1 8}$ \\
\hline Wardah & 2.9 & 4.5 & 13.0 & 14.9 & 22.3 & 25.0 & 36.2 \\
Revlon & 14.6 & 16.8 & 12.6 & 12.8 & 13.3 & 12.7 & 10.7 \\
Pixy & 10.3 & 10.8 & 9.0 & 11.0 & 9.3 & 9.6 & - \\
Viva & 9.8 & 8.3 & 8.2 & - & 8.9 & 8.8 & 7.6 \\
Sariayu & 8.8 & 8.0 & 9.2 & 7.6 & 7.7 & 7.5 & 7.2 \\
Oriflame & 7.0 & 7.4 & 6.6 & 7.7 & 6.5 & 5.7 & - \\
La Tulipe & 4.7 & 4.2 & 5.3 & 7.3 & 5.5 & 5.1 & - \\
Mirabella & 10.1 & 8.2 & 7.8 & - & - & - & 7.5 \\
\hline
\end{tabular}

Sumber: http://www.topbrand-award.com

Tabel 1. menampilkan perkembangan brand image Wardah yang mengalami peningkatan signifikan. Berbeda dengan produk lainnya yang mengalami perkembangan yang fluktuatif. Hal ini menunjukkan bahwa Wardah 
serius dalam membuat sebuah produk. Inovasi yang di produksi juga tidak selalu samaserta tanpa mengurangi kualitas dari produk tersebut. Hasil tersebut juga menandakan bahwa lipstik Wardah memiliki brand image yang cukup kuat terbukti dengan indeks Top Brand Index (TBI) yang selalu meningkat setiap tahun. Peningkatan perkembangan dari produk lipstik Wardah tidak terlepas dari kesuksesan celebrity yang mempromosikan kepada masyarakat. Salah satu Celebrity endorser yang mempromosikan produk lipstik Wardah dan dikenali oleh masyarakat adalah Dewi Sandra. Selain karena kecantikan paras yang dimiliki, Dewi Sandra juga merupakan sosok yang menginspirasi masyrakarat dengan kegiatan dan sikapnya yang baik. Kedua hal tersebut yang menyebabkan keyakinan dari masyarakat akan kualitas dari produk lipstik Wardah dan meningkatkan niat beli dari konsumen.

Untuk mengetahui penyebab terjadinya hal tersebut terjadi maka dilakukan pra survey menggunakan variabel celebrity endorser, brand image, dan purchase intention. Pra survey yang dilakukan kepada 30 orang responden terhadap celebrity endorser, didapatkan hasil bahwa 17 orang responden menyatakan tidak tertarik membeli lipstik Wardah karena faktor celebrity endorser. Berbeda halnya dengan hasil pra survey yang dilakukan kepada 30 orang responden mengenai brand image yaitu 27 orang responden membeli produk lipstik Wardah karena brand imagenya yang baik. Semua hasil pra survey tersebut menandakan bahwa celebrity endorser kurang mampu mempengaruhi purchase intention, sedangkan brand image mampu mempengaruhi purchase intention. Oleh sebab itu maka berdasarkan latar belakang tersebut, peneliti tertarik melakukan penelitian lebih lanjut mengenai peran brand image memediasi pengaruh celebrity endorser terhadap purchase intention.

Pokok permasalahan yang dirumuskan meliputi : 1) Bagaimana celebrity endorser berpengaruh terhadap brand image pada produk lipstik Wardah dikota Denpasar?; 2) Bagaimana celebrity endorser berpengaruh terhadap purchase intention pada produk lipstik Wardah di kota Denpasar?; 3) Bagaimana brand image berpengaruh terhadap purchase intention lipstik Wardah di kota Denpasar?; 4) Bagaimana celebrity endorser berpengaruh terhadap purchase intention yang di mediasi brand image pada produk lipstik Wardah di Kota Denpasar?

Adapun tujuan yang diharapkan penelitian ini yaitu mendapatkan bukti empiris pengaruh celebrity endorser terhadap brand image, mendapatkan bukti empiris pengaruh celebrity endorser terhadap purchase intention, mendapatkan bukti empiris pengaruh brand image terhadap purchase intention, dan mendapatkan bukti empiris pengaruh celebrity endorser terhadap purchase intention yang di mediasi brand image.

Penelitian ini memiliki dua manfaat yakni manfaat teoritis dan praktis. Secara teoritis, penelitian ini diharapkan dapat memberikan bukti empiris peran brand image memediasi pengaruh celebrity endorser terhadap purchase intention calon konsumen lipstik Wardah di kota Denpasar. Diharapkan juga agar menjadi referensi bagi pihak yang berkepentingan atau membutuhkan. Secara praktis diharapkan dapat dijadikan referensi kepada perusahaan yang memproduksi lipstik Wardah agar nantinya bisa lebih meningkatkan mutu serta kualitas dari 
produk yang dihasilkan dan dapat dijadikan sebagai informasi yang baik kepada masyarakat yang menggunakan produk tersebut.

Dukungan celebrity dianggap sebagai formula untuk memenangkan pemasaran merek, pembangunan merek dan meningkat pemasaran dari waktu ke waktu (Ashfaq dan Ali, 2017). Celebrity endorser sebagai sumber langsung adalah seseorang yang menyampaikan pesan sebuah produk atau jasa (Belch, 2004:116). Celebrity endorser adalah daya tarik iklan yang digunakan pemasar untuk memasarkan produk dengan tujuan membangun niat beli konsumen terhadap produk tersebut (Stephanie et al., 2013). Celebrity endorser adalah seseorang yang berbicara mengenai produk dan akan mempengaruhi sikap konsumen terhadap suatu produk yang didukungnya (Kotler dan Keller, 2009:216). Ada 3 indikator celebrity endorser yaitu: 1) Kredibilitas, 2) Karisma, dan 3) Kekuatan (Belch, 2004:216).

Pemasar memandang brand image sebagai pedoman konsumen dalam menilai kualitas produk atau layanan yaitu, petunjuk eksternal dari produk pemahaman adalah bahwa konsumen akan memanfaatkan brand image untuk menyimpulkan kesadaran merek dari produk atau layanan. Selain itu, brand image dapat dilihat sebagai satu set relative lokalisasi, kualitas identik penjaminan, dan atribut fungsi dari produk dan layanan konsumen mencerminkan citra diri mereka dan membantu membuat keputusan pembelian.

Brand image memiliki sifat khas yang membedakan suatu produk dengan produk yang lainnya walaupun sejenis (Haryantana dan Ekawati, 2015). Terdapat 4 indikator brand image yaitu: 1) Daya ingat konsumen akan merek, 2) Kualitas, 3) Citra produk, dan 4) Keunikan (Shimp, 2014:40).

Niat beli adalah perilaku yang dimiliki konsumen dalam mendasari keputusan pembelian yang akan dilakukan (Fure, 2013). Konsumen akan mengumpulkan informasi tentang produk yang akan menjadi pertimbangan sebelum melakukan pembelian. Indikator niat beli seorang konsumen adalah: 1) Ketertarikan mencari informasi, 2) Pertimbangan untuk membeli, 3) Keinginan untuk mengetahui, 4) Ketertarikan untuk mencoba, dan 5) Keinginan untuk memiliki (Schiffaman dan Kanuk, 2006). Model penelitian ini disusun seperti berikut:

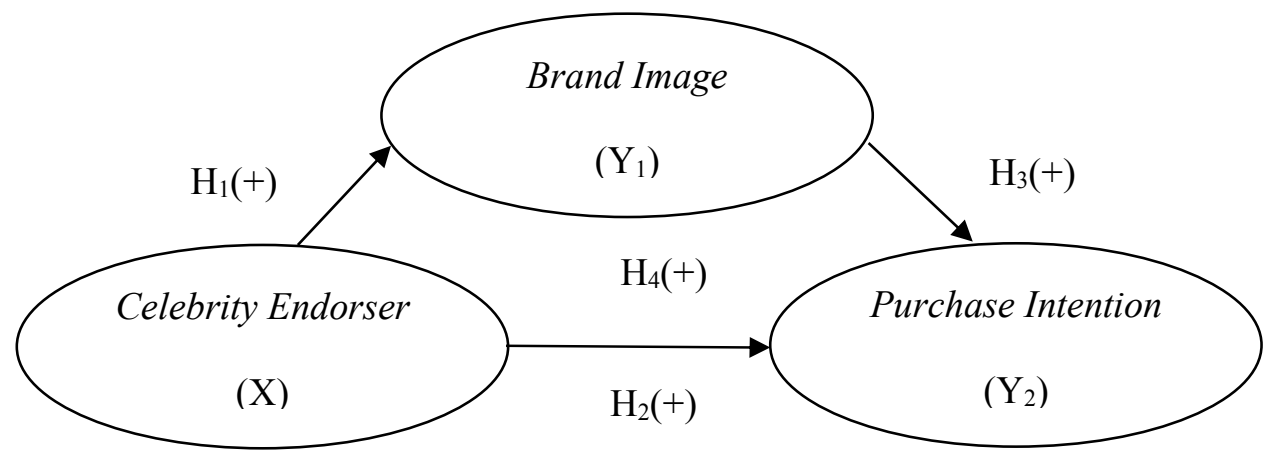

Gambar 1 .Kerangka Konsep Penelitian

Sumber: Hansudoh, 2012 
Dukungan dari celebrity endorser yang dilakukan mampu untuk meningkatkan brand image produk yang diiklankan. Ashfaq dan Ali (2017) menyatakan terdapat pengaruh positif dan signifikan antara celebrity endorser dengan brand image. Penelitian dari Cholifah et al. (2016) menghasilkan bahwa celebrity endorser berpengaruh positif dan signifikan terhadap brand image. Kara et al. (2013) juga menunjukkan celebrity endorser berpengaruh positif dan signifikan terhadap brand image. Berbeda dengan hasil penelitian dari Till dan Shimp (2014) serta Yang et al. (2012), variabel Celebrity Endorser tidak berpengaruh terhadap Brand Image. Hipotesis yang dapat diberikan pada penelitian ini yaitu:

$\mathrm{H}_{1:}$ Celebrity endorser berpengaruh positif dan signifikan terhadap brand image

Penelitian yang dilakukan Hansudoh (2012) dan Rodriguez (2008) didapatkan celebrity endorser berpengaruh positif dan signifikan terhadap purchase intention. Berbeda dengan Richardson et al. (2013), serta Nurani dan Haryanto (2010), menyatakan bahwa Celebrity Endorser tidak berpengaruh signifikan terhadap Purchase Intention. Hipotesis yang dapat diberikan pada penelitian ini yaitu:

$\mathrm{H}_{2}$ : Celebrity endorser berpengaruh positif dan signifikan terhadap purchase intention

Brand image yang positif dalam suatu produk, berdampak pada niat untuk membeli yang akan semakin tinggi pula. Wang dan Tsai (2014), Wu (2015), serta Rehman dan Ishaq (2017) menyatakan bahwa brand image meningkatkan niat pembelian. Hipotesis yang dapat diberikan pada penelitian ini yaitu:

$\mathrm{H}_{3:}$ Brand image berpengaruh positif dan signifikan terhadap purchase intention.

Wahyu dan Suparna (2014) mengatakan bahwa brand image mampu memediasi celebrity endorser terhadap purchase intention. Penelitian dari Ruslim dan Richard (2012) juga menunjukkan hasil sama yaitu terdapat hubungan celebrity endorser terhadap purchase intention dan mampu dimediasi brand image. Hipotesis yang dapat diberikan pada penelitian ini adalah:

$\mathrm{H}_{4}$ : Celebrity endorser berpengaruh positif dan signifikan terhadap purchase Intention

\section{METODE PENELITIAN}

Desain penelitian menggunakan pendekatan kuantitatif bersifat asosiatif. Penelitian ini membahas peran brand image memediasi pengaruh celebrity endorser terhadap purchase intention. Kota Denpasar sebagai lokasi penelitian adalah pusat kota yang memiliki tingkat pendapatan penduduk rata-rata menengah ke atas dan memiliki aktivitas pertumbuhan penduduk terpadat yaitu mencapai 7.155 jiwa per-km² yang diakses dari www.bali.bps.go.id tahun 2017. Obyek dalam penelitian ini yaitu mengenai purchase intention pada produk lipstik Wardah melalui brand image yang dipengaruhi oleh celebrity endorser.

Variabel yang diteliti adalah variabel eksogen yaitu Celebrity Endorser (X) dan variabel endogen yaitu Brand Image ( $\left.\mathrm{Y}_{1}\right)$ serta Purchase Intention $\left(\mathrm{Y}_{2}\right)$. Celebrity endorser merupakan seorang tokoh yang dikenal masyarakat serta memiliki kemampuan yang baik dalam mempromosikan suatu produk lipstik 
Wardah. Terdapat indikator untuk mengukur celebrity endorser yaitu 1) Credibility $\left.\left(\mathrm{X}_{1.1}\right), 2\right)$ Attractiveness $\left(\mathrm{X}_{1.2}\right)$, dan 3$)$ Power $\left(\mathrm{X}_{1.3}\right)$.

Brand image adalah kegiatan yang telah dilakukan oleh Wardah untuk meningkatkan citra merek. Terdapat 4 indikator dalam mengukur brand image yaitu 1) Produk yang berkualitas $\left(\mathrm{Y}_{1.1}\right)$, 2) Produk yang populer $\left.\left(\mathrm{Y}_{1.2}\right), 3\right)$ Produk yang memiliki variasi $\left(\mathrm{Y}_{1.3}\right)$, dan 4$)$ Produk yang bermanfaat $\left(\mathrm{Y}_{1.4}\right)$.

Purchase intention adalah tahapan konsumen untuk bertindak sebelum terjadi keputusan membeli produk lipstik Wardah. Terdapat 5 indikator untuk mengukur variabel purchase intention, diantaranya: 1)Ketertarikan mencari informasi $\left.\left(\mathrm{Y}_{2.1}\right), 2\right)$ Mempertimbangkan untuk membeli $\left.\left(\mathrm{Y}_{2.2}\right), 3\right)$ Keinginan untuk mengetahui $\left(\mathrm{Y}_{2.3}\right)$, 4) Ketertarikan untuk mencoba $\left(\mathrm{Y}_{2.4}\right)$, dan 5) Keinginan untuk memiliki $\left(\mathrm{Y}_{2.5}\right)$.

Populasi penelitian ini yaitu masyarakat di Kota Denpasar. Teknik penentuan sampel adalah nonprobability sampling, teknik samplingnya adalah purposive sampling. Sampel yang digunakan sebanyak 108 responden, dengan kriteria sampel yaitu berdomisili di Kota Denpasar, berjenis kelamin wanita, berumur 17 tahun ke atas, dan belum pernah menggunakan lipstik Wardah.

Jenis data yang digunakan adalah data kuantitatif atau hasil dari jawaban kuesioner. Penelitian menggunakan sumber data primer yaitu jawaban kuesioner. Teknik pengambilan data dilakukan berupa wawancara, kuesioner, pengamatan, dan juga menggunakan instrumen pengukuran yang dirancang sesuai tujuannya (Sugiyono, 2016:223). Metode pengumpulan data menggunakan survey.

Data yang diuji akan diolah degan program SPSS. Teknik analisis dalam penelitian ini yaitu teknik analisis jalur (Path Analysis). Pengujian hipotesis memediasi dilakukan dengan Uji Sobel (Sobel Test). Model hipotesis untuk pengambilan keputusan dalam pengujian hipotesis dalam penelitian ini adalah:

$\mathrm{H}_{0} \quad$ : Celebrity endorser tidak mampu memediasi pengaruh variabel brand image terhadap purchase intention.

$\mathrm{H}_{1} \quad$ : Celebrity endorser mampu memediasi pengaruh variabel brand image terhadap purchase intention.

Rumus standard error tidak langsung $\mathrm{S}_{\mathrm{ab}}$ adalah:

$$
\mathrm{S}_{\mathrm{ab}}=\sqrt{b^{2} S_{a}^{2}+a^{2} S_{b}^{2}+S_{a}^{2} S_{b}^{2}}
$$

Pengujian signifikansi pengaruh tidak langsung dilakukan menggunakan nilai $\mathrm{z}$ dari koefisien $\mathrm{ab}$ dan dihitung dengan rumus:

$$
\mathrm{z}=\frac{a b}{S a b}
$$

Keterangan:

$\mathrm{S}_{\mathrm{ab}} \quad=$ standar error tidak langsung

$\mathrm{S}_{\mathrm{a}} \quad=$ standar error koefisien a

$\mathrm{S}_{\mathrm{b}} \quad=$ standar error koefisien $\mathrm{b}$

a $\quad=$ koefisien jalur $\mathrm{X}_{1}$ terhadap $\mathrm{Y}_{1}$

$\mathrm{b} \quad=$ koefisien jalur $\mathrm{Y}_{1}$ terhadap $\mathrm{Y}_{2}$ 
$\mathrm{ab} \quad=$ hasil kali koefisien jalur $\mathrm{X}$ terhadap koefisien jalur $\mathrm{Y}_{1}(\mathrm{a})$ dengan jalur $\mathrm{Y}_{1}$ terhadap $\mathrm{Y}_{2}(\mathrm{~b})$.

\section{HASIL DAN PEMBAHASAN}

Penelitian dilakukan untuk mendapat bukti empiris pengaruh Celebrity Endorser terhadap Purchase Intention yang di mediasi Brand Image. Jumlah responden dalam penelitian ini adalah 108 orang. Responden telah memenuhi kriteria yang telah ditetapkan diantaranya berdomisili di Kota Denpasar, berusia 17 tahun keatas, tidak pernah melakukan pembelian lipstik Wardah dan berniat membeli lipstik Wardah.

Tabel 2.

Karakteristik Responden

\begin{tabular}{|c|c|c|c|c|}
\hline No & Variabel & Klasifikasi & $\begin{array}{c}\text { Jumlah } \\
\text { (Orang) }\end{array}$ & $\begin{array}{c}\text { Persentase } \\
(\%)\end{array}$ \\
\hline \multirow{4}{*}{1} & \multirow{4}{*}{ Usia (tahun) } & $17-23$ & 100 & 92.59 \\
\hline & & $24-29$ & 3 & 2.78 \\
\hline & & $30-35$ & 0 & 0.00 \\
\hline & & $\geq 36$ Tahun & 5 & 4.63 \\
\hline \multicolumn{3}{|c|}{ Jumlah } & 108 & 100 \\
\hline \multirow{5}{*}{2} & \multirow{4}{*}{ Pekerjaan } & Pelajar/Mahasiswa & 94 & 87.04 \\
\hline & & Wiraswasta & 4 & 3.70 \\
\hline & & PNS & 2 & 1.85 \\
\hline & & Lainnya & 8 & 7.41 \\
\hline & \multicolumn{2}{|c|}{ Jumlah } & 108 & 100 \\
\hline
\end{tabular}

Sumber: Data Primer, 2018

Tabel 2. menunjukkan bahwa dalam penelitian ini di dominasi oleh responden yang berusia 17-23 tahun dengan presentase 92,59 persen. Hasil tersebut menunjukkan bahwa responden dengan rentang usia tersebut sangat berniat membeli kosmetik, salah satunya adalah lipstik Wardah. Klasifikasi pekerjaan didominasi oleh pelajar/mahasiswa dengan jumlah 94 orang atau 87,04 persen. Hal tersebut menunjukkan bahwa semakin banyak penggunaan lipstik dikalangan pelajar/mahasiswa dibandingkan dengan pekerjaan lainnya.

Uji validitas dilakukan dalam memeriksa pengukuran indikator di dalam instrument berupa kuesioner.

Tabel 3.

Hasil Uji Validitas

\begin{tabular}{|c|c|c|c|c|}
\hline Nis & 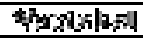 & boitisoosy & 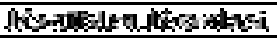 & 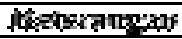 \\
\hline \multirow{3}{*}{ ]. } & \multirow{3}{*}{ 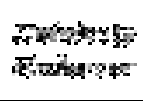 } & 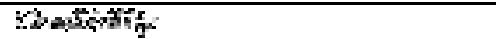 & 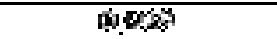 & 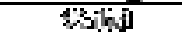 \\
\hline & & 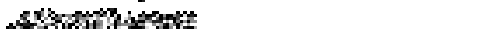 & 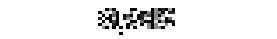 & extivi \\
\hline & & Pistion & gisisy & 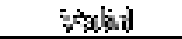 \\
\hline \multirow{4}{*}{$\$$} & \multirow{4}{*}{ 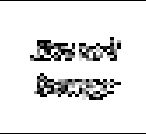 } & 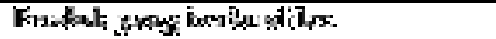 & Distive & 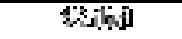 \\
\hline & & Eaysugeng paralyx & 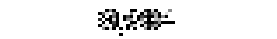 & estiol \\
\hline & & 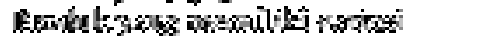 & bismę & 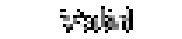 \\
\hline & & 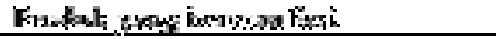 & 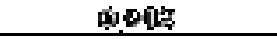 & 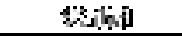 \\
\hline \multirow{5}{*}{8} & \multirow{5}{*}{ 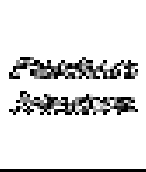 } & 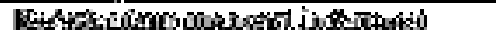 & 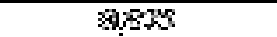 & 2activi \\
\hline & & 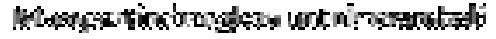 & butas & 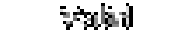 \\
\hline & & 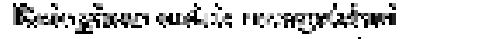 & 的现公 & 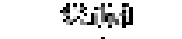 \\
\hline & & 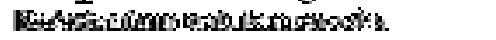 & 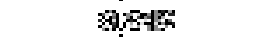 & estivil \\
\hline & & 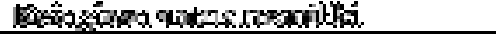 & 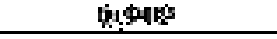 & 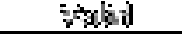 \\
\hline
\end{tabular}

Sumber: Data Primer diolah, 2018 
Tabel 3. menunjukkan bahwa semua instrumen penelitian yang digunakan dalam mengukur variabel penelitian (Celebrity Endorsers, Brand Image dan Purchase Intantione) memiliki nilai koefisien korelasi diatas 0,3 dan dinyatakan valid.

Uji reliabilitas dilakukan untuk mengetahui konsisten suatu alat ukur dalam penggunaannya. Instrumen yang digunakan berulang-ulang dalam mengukur objek dan menghasilkan jawaban yang sama adalah instrument yang reliabel.

Tabel 4.

Hasil Uji Reliabilitas

\begin{tabular}{clcc}
\hline No & \multicolumn{1}{c}{ Variabel } & Cronbach's Alpha & Keterangan \\
\hline 1 & Celebrity Endorser & 0,929 & Reliabel \\
2 & Brand Image & 0,905 & Reliabel \\
3 & Purchase Intention & 0,920 & Reliabel \\
\hline
\end{tabular}

Sumber: Data Primer diolah 2018

Berdasarkan Tabel 4. ketiga variabel telah memenuhi syarat konsistensi dan keandalan data. Nilai Cronbach's alpha keseluruhan variabel $>0,6$ dan dinyatakan reliabel, sehingga mampu digunakan sebagai instrument penelitian.

Celebrity endorser merupakan variabel eksogen yang diukur menggunakan 3 indikator dalam mengetahui jawaban responden.

Tabel 5.

Penilaian Responden terhadap Variabel Celebrity Endorser

\begin{tabular}{lccccccc}
\hline \multirow{2}{*}{ Indikator } & \multicolumn{5}{c}{ Skor Jawaban } & \multirow{2}{*}{ Rata-Rata } & \multirow{2}{*}{ Keterangan } \\
\cline { 2 - 7 } Credibility $\left(\mathrm{X}_{1.1}\right)$ & 1 & 2 & 3 & 4 & 5 & & Baik \\
Attractiveness $\left(\mathrm{X}_{2 \cdot 2}\right)$ & 3 & 9 & 19 & 58 & 19 & 3,75 & Baik \\
Power $\left(\mathrm{X}_{3.3}\right)$ & 5 & 3 & 15 & 57 & 28 & 3,93 & Baik \\
& 3 & 11 & 23 & 53 & 18 & 3,67 & Baik \\
\hline
\end{tabular}

Sumber: Data Primer diolah 2018

Tabel 5. menunjukkan data variabel celebrity endorser yaitu nilai rata-rata adalah 3,78. Nilai tersebut dalam kategori baik, artinya responden mempunyai persepsi yang baik pada celebrity endorser lipstik Wardah.

Brand image merupakan variabel yang mempengaruhi variabel purchase intention dan diukur dengan menggunakan 4 indikator.

Tabel 6.

Penilaian Responden terhadap Brand Image

\begin{tabular}{lcccccccc}
\hline \multirow{2}{*}{ Indikator } & \multicolumn{6}{c}{ Skor Jawaban } & \multirow{2}{*}{ Rata-Rata } & \multirow{2}{*}{ Keterangan } \\
\cline { 2 - 6 } & 1 & 2 & 3 & 4 & 5 & & \\
\hline Produk yang berkualitas $\left(\mathrm{Y}_{1.1}\right)$ & 0 & 8 & 27 & 55 & 17 & 3,76 & Baik \\
Produk yang popular $\left(\mathrm{Y}_{1.2}\right)$ & 3 & 12 & 32 & 42 & 19 & 3,57 & Baik \\
Produk yang memiliki variasi $\left(\mathrm{Y}_{1.3}\right)$ & 3 & 8 & 14 & 52 & 31 & 3,93 & Baik \\
Produk yang bermanfaat $\left(\mathrm{Y}_{1.4}\right)$ & 0 & 8 & 31 & 55 & 14 & 3,69 & Baik \\
\hline \multicolumn{1}{c}{ Total } & & & & & & 3,74 & Baik \\
\hline
\end{tabular}

Sumber: Data Primer diolah 2018 
Tabel 6. menunjukkan data variabel brand image yaitu nilai rata-rata adalah 3,74. Nilai termasuk kategori baik, artinya responden mempunyai persepsi baik pada brand image produk lipstik Wardah.

Purchase intention adalah variabel endogen yang dipengaruhi oleh celebrity endorser dan diukur menggunakan 5 indikator.

Tabel 7.

Penilaian Responden terhadap Purchase Intention

\begin{tabular}{|c|c|c|c|c|c|c|c|}
\hline \multirow{2}{*}{ Indikator } & \multicolumn{5}{|c|}{ Skor Jawaban } & \multirow{2}{*}{ Rata-Rata } & \multirow{2}{*}{ Keterangan } \\
\hline & 1 & 2 & 3 & 4 & 5 & & \\
\hline $\begin{array}{l}\text { Ketertarikan mencari informasi } \\
\left(\mathrm{Y}_{2.1}\right)\end{array}$ & 2 & 6 & 23 & 56 & 21 & 3,81 & Baik \\
\hline $\begin{array}{l}\text { Mempertimbangkan untuk } \\
\text { membeli }\left(\mathrm{Y}_{2.2}\right)\end{array}$ & 5 & 8 & 21 & 56 & 18 & 3,69 & Baik \\
\hline Keinginan untuk mengetahui $\left(\mathrm{Y}_{2.3}\right)$ & 1 & 6 & 20 & 54 & 27 & 3,93 & Baik \\
\hline Ketertarikan untuk mencoba $\left(\mathrm{Y}_{2.4}\right)$ & 1 & 5 & 15 & 56 & 31 & 4,03 & Baik \\
\hline Keinginan untuk memiliki $\left(\mathrm{Y}_{2.5}\right)$ & 1 & 10 & 16 & 46 & 35 & 3,96 & Baik \\
\hline Total & & & & & & 3,88 & Baik \\
\hline
\end{tabular}

Sumber: Data Primer diolah 2018

Tabel 7. menunjukkan data variabel purchase intention yaitu nilai rata-rata total adalah 3,88. Nilai termasuk kategori baik, artinya responden mempunyai persepsi baik pada purchase intention lipstik Wardah.

Path analysis yaitu pengembangan analisis regresi linear berganda yang menguji persamaan regresi. Data yang telah diolah dan dihitung akan menunjukkan hasil analisis seperti berikut.

Hasil Analisis Jalur Persamaan Regresi 1

$$
\begin{array}{lllll}
\hat{\mathrm{Y}}_{1} & =0,574 \mathrm{X} & & \\
\mathrm{S}(\beta) & =(0,71) & & \\
\mathrm{t} & =(7,219) & & & \\
\mathrm{Sig} & =(0,000) & & & \\
\mathrm{R}^{2} & =0,330 & \mathrm{df}=106 & \mathrm{~F}=52,120 & \mathrm{Sig}=0,000
\end{array}
$$

Perhitungan $\mathrm{F}$ menghasilkan angka sebesar 52,120, dan signifikansi 0,000 yang lebih kecil dari 0,05. Ini berarti bahwa variabel celebrity endorser (X) berpengaruh terhadap brand image $\left(\mathrm{Y}_{1}\right)$. Koefisien determinasi atau $\mathrm{R}^{2}=0,330$ memiliki arti bahwa 33 persen brand image dipengaruhi oleh celebrity endorser, sedangkan 67 persen dipengaruhi faktor lain yang tidak dimasukkan dalam model.

Angka tersebut dapat menjelaskan bahwa variabel celebrity endorser (X) berpengaruh positif terhadap brand image $\left(\mathrm{Y}_{1}\right)$ produk lipstik Wardah. Apabila kredibilitas dari seorang celebrity endorser mengalami peningkatan maka pengaruh positif pada brand image dari produk lipstik Wardah juga akan meningkat.

Hasil Analisis Jalur Persamaan Regresi 2

$$
\begin{array}{ll}
\hat{\mathrm{Y}}_{2} & =0,478 \mathrm{X}+0,355 \mathrm{Y}_{1} \\
\mathrm{~S}(\beta) & =(0,072)(0,080) \\
\mathrm{t} & =(5,981)(4,434) \\
\mathrm{Sig} & =(0,000)(0,000) \\
\mathrm{R}^{2} & =0,550 \mathrm{df}=105 \quad \mathrm{~F}=64,056 \quad \mathrm{Sig}=0,000
\end{array}
$$


Perhitungan $\mathrm{F}$ menghasilkan angka sebesar 64,056, dan signifikansi 0,000 jauh lebih kecil dari 0,05. Artinya secara serempak celebrity endorser $(\mathrm{X})$ dan brand image $\left(\mathrm{Y}_{1}\right)$ berpengaruh terhadap purchase intention $\left(\mathrm{Y}_{2}\right)$. Koefisien determinasi atau $\mathrm{R}^{2}=0,550$ memiliki arti yaitu 55 persen variabel purchase intention dipengaruhi oleh variabel celebrity endorser serta variabel brand image, sedangkan 45 persen dipengaruhi faktor lain yang tidak dimasukkan dalam model.

Angka-angka tersebut menjelaskan bahwa celebrity endorser $(\mathrm{X})$ dan brand image $\left(\mathrm{Y}_{1}\right)$ berpengaruh sangat nyata terhadap purchase intention. Apabila power yang diberikan oleh celebrity endorser serta kualitas dari brand image tersebut meningkat dengan baik maka akan berpengaruh positif terhadap purchase intention dari konsumen pada produk lipstik Wardah.

Pengaruh Langsung. Pengaruh celebrity endorser $(\mathrm{X})$ terhadap brand image $\left(\mathrm{Y}_{1}\right)$ yaitu $\beta_{1}=0,574$, Pengaruh celebrity endorser $(\mathrm{X})$ terhadap purchase intention $\left(\mathrm{Y}_{2}\right)$ yaitu $\beta_{2}=0,478$, Pengaruh brand image $\left(\mathrm{Y}_{1}\right)$ terhadap purchase intention $\left(\mathrm{Y}_{2}\right)$ yaitu $\beta_{3}=0,355$.

Pengaruh Tidak Langsung. Pengaruh celebrity endorser (X) terhadap purchase intention $\left(\mathrm{Y}_{2}\right)$ dengan brand image $\left(\mathrm{Y}_{1}\right)$ sebagai pemediasi, adalah:

$$
\begin{aligned}
\text { Pengaruh Tidak Langsung } & =\beta_{1} \times \beta_{3} \ldots \ldots \ldots \\
& =0,574 \times 0,355 \\
& =0,203
\end{aligned}
$$

(3) Pengaruh Total

Total pengaruh celebrity endorser $(\mathrm{X})$ terhadap purchase intention $\left(\mathrm{Y}_{2}\right)$ melalui brand image $\left(\mathrm{Y}_{1}\right)$, adalah:

Pengaruh Total $=\beta_{2}+\left(\beta_{1} \times \beta_{3}\right)$

$$
\begin{aligned}
& =0,478+(0,574 \times 0,355) \\
& =0,681
\end{aligned}
$$

Hasil analisis jalur substruktur 1 dan 2 telah dihitung dan telah disusun model diagram jalur akhir. Standar error dihitung sebelum menyusun model diagram jalur akhir yaitu:

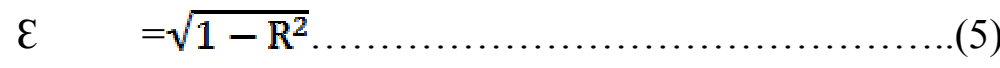

$$
\begin{aligned}
& \varepsilon_{1}=\sqrt{1-\mathrm{R}_{1}^{2}} \\
& =\sqrt{1-0,330} \\
& =0,67 \\
& \varepsilon_{2} \quad=\sqrt{1-\mathrm{R}_{2}^{2}} \text {. } \\
& =\sqrt{1-0,550} \\
& =0,45
\end{aligned}
$$

Perhitungan standar error $(\varepsilon)$ didapatkan pengaruh error $1\left(\mathrm{e}_{1}\right)$ yaitu 0,67 serta pengaruh error $2\left(\mathrm{e}_{2}\right)$ yaitu 0,45 . Perhitungan nilai koefisien determinasi total adalah:

$$
\begin{aligned}
\mathrm{R}^{2} \mathrm{~m} & =1-\left(\mathrm{P} \varepsilon_{1}\right)^{2}\left(\mathrm{PE}_{2}\right)^{2} \ldots \ldots \\
& =1-(0,67)^{2}(0,45)^{2} \\
& =1-(0,4489)(0,2025) \\
& =1-0,09090225 \\
& =0,90909775 / 0,909
\end{aligned}
$$


Nilai koefisien determinasi total sebesar 0,909 berarti 90,9 persen variabel Purchase Intention dipengaruhi variabel Celebrity Endorser dan Brand Image, sedangkan 9,1 persen dijelaskan faktor lain yang tidak dimasukkan ke dalam model.

Kriteria pengujian dalam interpretasi pengaruh masing-masing variabel adalah jika Sig. $\mathrm{t}<0,05$ maka $\mathrm{H}_{0}$ ditolak sedangkan $\mathrm{H}_{1}$ diterima dan jika Sig. $\mathrm{t}>$ 0,05 maka $\mathrm{H}_{0}$ diterima sedagkan $\mathrm{H}_{1}$ ditolak.

Pengaruh celebrity endorser terhadap brand image. Hubungan celebrity endorser terhadap brand image diperoleh nilai koefisien beta 0,574 , nilai signifikan t $0,000<0,05$ sehingga $\mathrm{H}_{1}$ diterima sedangkan $\mathrm{H}_{0}$ ditolak. Hasil tersebut menunjukkan bahwa terdapat hubungan yang positif dan signifikan antara celebrity endorser terhadap brand image.

Pengaruh brand image terhadap purchase intention. Hasil analisis hubungan brand image terhadap purchase intention diperoleh nilai koefisien beta sebesar 0,355 dan nilai signifikan $\mathrm{t}$ 0,000 lebih kecil dari 0,05 sehingga $\mathrm{H}_{1}$ diterima sedangkan $\mathrm{H}_{0}$ ditolak. Hasil tersebut menunjukkan bahwa terdapat hubungan yang positif dan signifikan antara brand image terhadap purchase intention.

Pengaruh celebrity endorser dengan purchase intention. Hubungan celebrity endorser terhadap purchase intention diperoleh nilai koefisien beta 0,478 dan nilai signifikan t $0,000>0,05$ sehingga $\mathrm{H}_{0}$ ditolak sedangkan $\mathrm{H}_{1}$ diterima. Hasil itu menunjukkan bahwa hubungan yang positif dan signifikan antara celebrity endorser terhadap purchase intention.

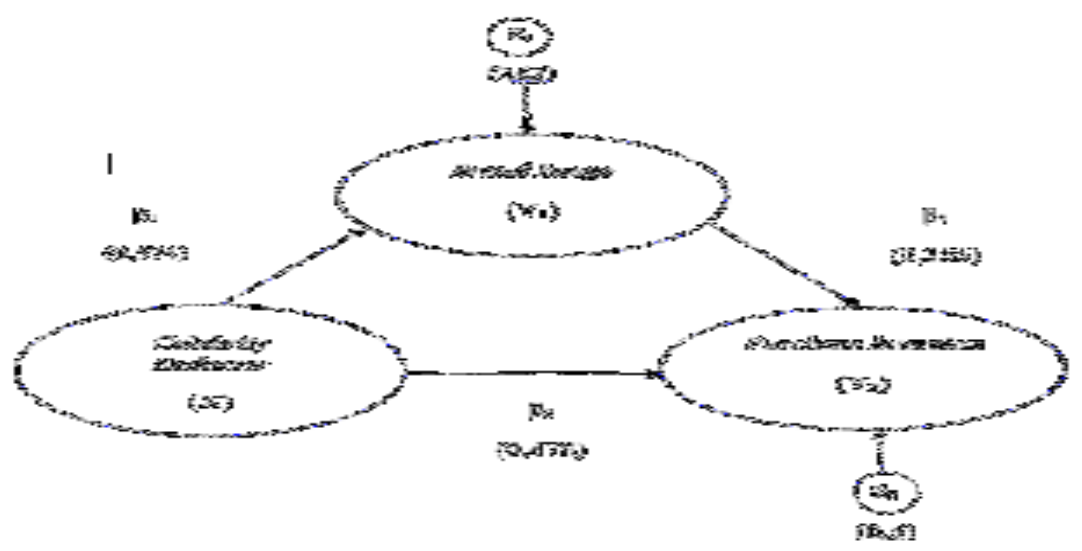

\section{Gambar 2. Validasi Model Diagram Jalur Akhir}

Berdasarkan Gambar 2 maka besarnya pengaruh langsung, pengaruh tidak langsung, dan pengaruh total antar variabel dapat dihitung.

Tabel 8. menunjukkan pengaruh langsung celebrity endorser terhadap purchase intention mempunyai nilai koefisien beta 0,478 , dan pengaruh tidak langsung yang dimediasi brand image menunjukkan koefisien beta 0,203. Hasil tersebut membuktikan brand image memediasi hubungan celebrity endorser terhadap purchase intention dengan pengaruh total yang diperoleh 0,681 . 
Tabel 8.

Pengaruh Langsung, Pengaruh Tidak Langsung, dan Pengaruh Total Celebrity Endorser (X), Brand Image (Y) dan Purchase Intention ( $\left.\mathrm{Y}_{2}\right)$

\begin{tabular}{lccc}
\hline $\begin{array}{c}\text { Pengaruh } \\
\text { Variabel }\end{array}$ & $\begin{array}{c}\text { Pengaruh } \\
\text { Langsung }\end{array}$ & $\begin{array}{c}\text { Pengaruh Tidak Langsung } \\
\text { Melalui Brand Image } \\
\left(\mathbf{Y}_{\mathbf{1}}\right)=\left(\boldsymbol{\beta}_{\mathbf{1}} \mathbf{x} \mathbf{\beta}_{\mathbf{2}}\right)\end{array}$ & $\begin{array}{c}\text { Pengaruh } \\
\text { Total }\end{array}$ \\
\hline $\mathrm{X} \longrightarrow$ & 0,574 \\
$\mathrm{X} \longrightarrow \mathrm{Y} 1$ & 0,574 & 0,203 & 0,681 \\
$\mathrm{Y} 1 \longrightarrow \mathrm{Y} 2$ & 0,478 & & 0,355 \\
\hline $\mathrm{S} 1 \mathrm{Y} 2$ & 0,355 & &
\end{tabular}

Sumber: Data Primer diolah, 2018

Berdasarkan analisis regresi tanpa variabel mediasi didapat pengaruh yang signifikan dari celebrity endorser terhadap purchase intention dengan koefisien jalur 0,478 dan signifikansi 0,000. Hasil laporan regresi stuktur 1 dan stuktur 2 juga didapat pengaruh signifikan dari celebrity endorser terhadap brand image dengan koefisien sebesar 0,574 dengan signifikansi 0,000. Demikian juga dari brand image terhadap purchase intention dengan koefisien jalur sebesar 0,355 serta signifikansi sebesar 0,000. Perhitungan uji sobel dalam penelitian ini adalah:

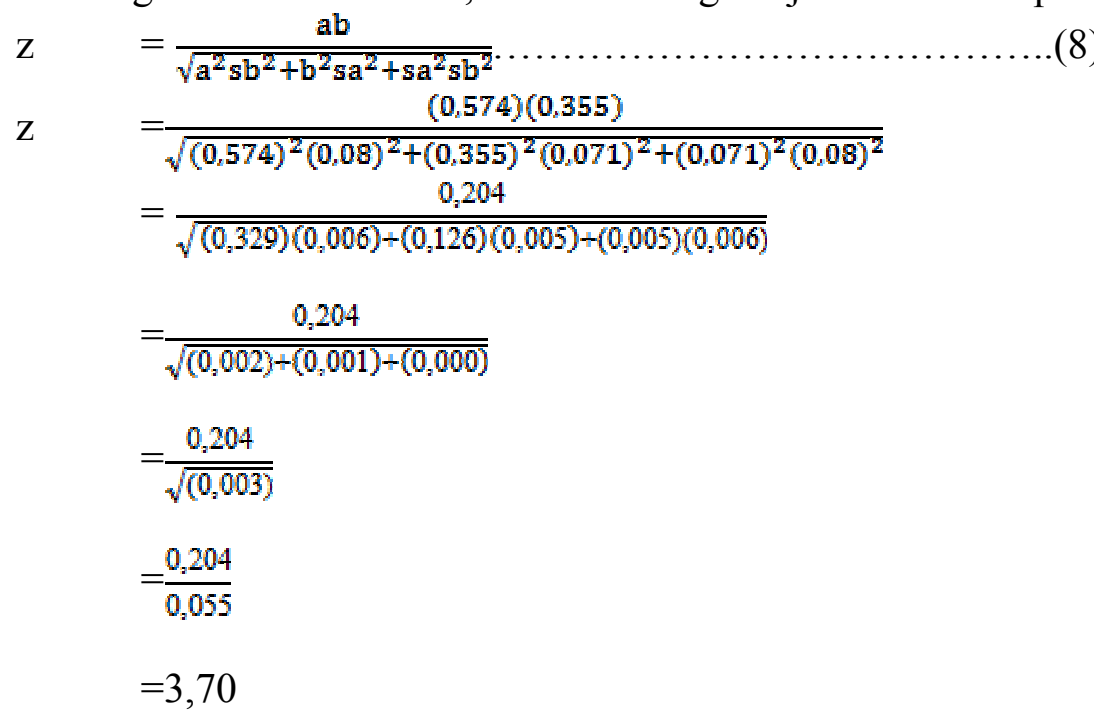

Hasil Uji Sobel yaitu nilai koefisen $\mathrm{z}$ adalah 3,70 $>1,96$ dan tingkat signifikansi $0,000<0,05$, sehingga $\mathrm{H}_{1}$ diterima serta $\mathrm{H}_{0}$ ditolak. Brand image dinilai signifikan memediasi pengaruh celebrity endorser terhadap purchase intention.

Hubungan antara celebrity endorser dengan brand image memiliki nilai koefisien beta 0,574 dan tingkat signifikansi $0,000 \leq 0,05$ sehingga $\mathrm{H}_{1}$ diterima dan $\mathrm{H}_{0}$ ditolak, artinya celebrity endorser berpengaruh positif serta signifikan terhadap brand image. Semakin baik celebrity endorser dalam mempromosikan produk lipstik Wardah, maka tingkat brand image terkait produk lipstik Wardah juga semakin tinggi. Hasil penelitian ini sesuai dengan yang dilakukan Cholifah et al. (2016), Hakimi et al. (2016) serta Kara (2013). Dalam penelitian Cholifah et al (2016), penelitian yang digunakan adalah explanatory research dengan pendekatan kuantitatif, tingkat signifikansi $0,000 \leq 0,05$ sehingga $\mathrm{H}_{1}$ diterima serta $\mathrm{H}_{0}$ ditolak dan hasil didapatkan dari penelitian ini bahwa celebrity endorser berpengaruh positif serta signifikan terhadap brand image. 
Hubungan antara brand image dengan purchase intention memiliki nilai koefisien beta 0,355 dan tingkat signifikansi $0,000 \leq 0,05$ sehingga $\mathrm{H}_{1}$ diterima dan $\mathrm{H}_{0}$ ditolak, artinya brand image berpengaruh positif serta signifikan terhadap purchase intention. Tingkat brand image lipstik Wardah yang semakin tinggi, tingkat purchase intention lipstik Wardah pada konsumen juga semakin tinggi. Hasil penelitian ini sesuai dengan yang dilakukan Ruslim dan Richard (2012), Bhakar et al. (2013), serta Febriyanti dan Aniek (2016). Dalam penelitian Ruslim dan Richard (2012), teknik pengambilan sampel adalah purposive sampling. Tingkat signifikansi $0,000 \leq 0,05$ sehingga $\mathrm{H}_{1}$ diterima serta $\mathrm{H}_{0}$ ditolak dan hasil yang didapatkan bahwa brand image berpengaruh positif serta signifikan terhadap purchase intention.

Hubungan antara celebrity endorser dengan purchase intention memiliki nilai koefisien beta 0,478 dan tingkat signifikansi $0,000 \leq 0,05$ sehingga $\mathrm{H}_{1}$ diterima dan $\mathrm{H}_{0}$ ditolak, yang artinya celebrity endorser berpengaruh positif dan signifikan terhadap purchase intention. Semakin baik celebrity endorser mempromosikan lipstik Wardah,maka semakin tinggi tingkat purchase intentionlipstik Wardah pada konsumen. Hasil penelitian ini diperkuat dengan penelitian dari Cholifah et al. (2016), Hakimi et al. (2016), serta Kara (2013). Dalam penelitian Cholifah et al. (2016), penelitian yang digunakan adalah explanatory research dengan pendekatan kuantitatif, tingkat signifikansi $0,000 \leq$ 0,05 sehingga $\mathrm{H}_{0}$ ditolak $\mathrm{H}_{1}$ diterima dan hasil yang didapatkan dari penelitian ini bahwa celebrity endorser berpengaruh positif serta signifikan terhadap brand image.

Semula hasil uji pengaruh celebrity endorser terhadap purchase intention bernilai 0,478. Munculnya brand image sebagai pemediasi, nilai pengaruh celebrity endorser terhadap purchase intention mengalami peningkatan 0,681 . Uji Sobel dilakukan untuk memperkuat hasil dengan nilai koefisien $\mathrm{z}$ adalah 3,70 > 1,96, artinya brand image mampu memediasi pengaruh celebrity endorser terhadap purchase intention lipstik Wardah. Hasil penelitian sesuai dengan penelitian Dei dan Sukaatmadja (2015), Wahyuni dan Suparna (2014), serta Wang dan Tsai (2014). Dalam penelitian Dei dan Sukaatmadja (2015), teknik pengambilan sampel adalah incidental dan purposive sampling. Tingkat signifikansi dengan nilai t statistik 3,825 $(>1,96)$ pada tingkat signifikansi alpha sama dengan 0,05 dan menyatakan brand image mampu secara signifikan memediasi hubungan celebrity endorser terhadap purchase intention.

Penelitian ini dapat memberikan kontribusi empiris hubungan antara variabel brand image, celebrity endorser, dan purchase intention bagi pengembangan ilmu pemasaran. Pengolahan data menggunakan teknik analisis jalur dalam memperkirakan hubungan kausalitas antara variabel yang ditetapkan sebelumnya berdasarkan teori. Selain itu Uji Sobel juga digunakan dalam menguji pengaruh tidak langsung variabel celebrity endorser (X) terhadap variabel purchase intention (Y2) melalui variabel brand image (Y1). Penelitian ini memberikan implikasi bagi produsen lipstik Wardah dalam memanfaatkan aspek celebrity endorser, brand image, sebagai strategi meningkatkan purchase intention terhadap produk lipstik Wardah. Perusahaan dapat melakukan strategi dengan memanfaatkan kredibilitas celebrity endorser sebagai sarana 
mempromosikan produk lipstik Wardah agar konsumen lebih percaya pada produk yang ditawarkan perusahaan.

\section{SIMPULAN DAN SARAN}

Dapat ditarik kesimpulan bahwa celebrity endorser berpengaruh positif terhadap purchase intention, celebrity endorser berpengaruh positif terhadap brand image, brand image berpengaruh positif terhadap purchase intentiondan peran brand image memediasi secara signifikan hubungan celebrity endorser dengan purchase intention.

Saran yang dapat diberikan adalah: 1) Pihak Wardah harus menekankan pada testimony dalam mempromosikan produk dan menggunakan celebrity endorser yang berpenampilan menarik agar konsumen berniat untuk membeli produk tersebut. 2) Pihak Wardah agar selalu memberkan inovasi baru terhadap produk yang ditawarkan sehingga dapat meningkatkan brand image. Inovasi yang baru tersebut akan membuat konsumen semakin tertarik membeli produk yang ditawarkan Wardah dibandingkan produk pesaing lainnya, 3) Pihak Wardah harus mempromosikan produk yang ditawarkan melalui media cetak serta media lainnya agar menimbulkan niat beli dari konsumen.

\section{REFERENSI}

Anindyakirana,Feby. (2016). Selama 100 Tahun Ini Peubahan Lisptik Dari Masa Ke Masa.https://www.vemale.com/cantik/91794-selama-100-tahun-iniperubahan-tren-lipstik-dari-masa-ke-masa.htmlDiakses 5 Agustus 2018

Ashfaq, M., \& Ali, M. (2017). Impact of Celebrity Endorsement on Consumer Buying Behavior in FMCG Sector of Pakistan. Arabian Journal of Business and Management Review (Oman Chapter), 7(1), 1-13.

Belch, Gorge E. \& Belch, Michael A. (2004). Advertising and Promotion: An integrated Marketing Comunication Prespective. New York: Mc. GrawHill/Irwin.

Bhakar, S.S., Bhakar, S \& Bhakar, S.(2013). Relationship Between Country of Origin, Brand image and Customer Purchase intention. Far East Research Centre.10(2), pp:25-30

Chan Kara, Yu Leung Ng, Edwin K. Luk. (2013). Impact of Celebrity Endorsement in advertising on brand imahage among chinese adolescents, Young Consumers. Departemen of Communication Studies Journal, 14 (2), pp:167-179.

Cholifah, Nike, Suharyono \& Kadarisman Hidayat. (2016) . Pengaruh Celebrity Endorse terhadap Brand Image (Survei pada konsumen Kosmetik Wardah di Counter Wardah Kota Malang). Jurnal Administrasi Bisnis, 36(1): hal:170-177. 
Dei, Gusti Ayu Theoria \& I Putu Gede Sukaatmadja, (2015). Peran Brand image Memediasi Pengaruh Kredibilitas Celebrity endorse Terhadap Purchase intention (Studi Pada Produk Kosmetik Etude di Kota Denpasar). E-Jurnal Manajemen Unud,4(5), hal:1206-1228

Febriyanti, Rizky Suci \& Aniek Wahyuati. (2016).Pengaruh Celebrity Endorse dan Brand image terhadap Keputusan Pembelian melalui minat beli. Jurnal Ilmu dan Riset Manajemen. 5(5), hall:18.

Fure, H. (2013). Lokasi, Keberagaman Produk, Harga, Dan Kualitas Pelayanan Pengaruh Terhadap Niat Beli pada Pasar Tradisional Calaca. Jurnal Emba, 1 (3), hal.273-283.

Hakimi, B.Y., Abedniya, A. and Zaeim, M.N. (2016). Investigate the impact of celebrity endorsment on brand images. European Journal of Scientific Research, 58 (1),pp: 16-32.

Hansudoh, S. A. (2012). Pengaruh Celebrity Endorsement Terhadap Purchase Intention Melalui Perceived Value pada Produk Top Coffee di Surabaya. Jurnal Ilmiah Mahasiswa Manajemen.

Haryantana, I Putu Gede Handre dan Ni Wayan Ekawati, (2015). Pengaruh Celebrity Endorser, Brand Image dan Persepsi Kualitas Terhadap Niat Beli Sepeda Motor Honda Scoopy di Kota Denpasar. E-Jurnal Manajemen Universitas Udayana, 4(9), hal: 2806-2830.

Herliza, Raditya dan Marheni Eka Saputri, ST., MBA.(2016). Pengaruh Brand Image terhadap Keputusan Pelanggan Studi pada Zara di Mall PVJ Bandung. Jurnal Manajemen Telkom University, 3(2), hal 1949-1955.

Kaur, S., \& Garg, A. (2016). Celebrity Endorsement And Buying Behavior: A Study Of Panjab University Students. International Journal of Research Granthaalayah, 4(11), 122-136.

Kotler, Philip dan Gray Amstrong. (2006). Dasar - Dasar Pemasaran, Edisi Keenam, Terjemahan Wilhelmus W Bakwanton, Jakarta, Intermedia.

Kotler dan Keller. (2009). Manajemen Pemasaran. Jilid I. Edisi ke 13 Jakarta: Erlangg.

Marcinda Ammy. (2017). Mengupas Filosopi Lipstik Bagi Wanita Indonesia di Sociolla Soiree Bersama Mustika Ratu matte Lip Cream https://journal.sociolla.com/beauty/sociolla-soiree-bersama-mustikaratu/Diakses 5 Agustus 2018

Nurani, Eka Setya \& Haryanto, Jony Oktavian. (2010). Pengaruh Celebrity Endorser, Brand Association, Brand Personality dan Product Characteristics Dalam Menciptakan Intensi Pembelian (Studi pada Iklan Kuku Bima Ener-G 
Rosa Versi Chris John). Journal of Business Strategy and Execution. 2(2). 104-125

Pracista, N. M., \& Rahanatha, G. B. (2014). Pengaruh Kredibilitas Celebrity Endorser, Daya Tarik Iklan, Dan Kepuasan Pelanggan Terhadap Ekuitas Merek ( Brand Equity ) Dari Produk Sampo L ' Oreal Pada Konsumen Perempuan. E-Journal Manajemen Universitas Udayana, 3(7), 1870-1885.

Rehman, Hafiz Ihsan Ur, \& Ishaq, Zahid. (2017). The Impact of Brand Image on Purchase Intention: Moderating Role of Store Image in Pakistan's Retail Sector. The IUP Journal of Brand Management, 14(3), 54-66.

Richardson, A., Miller, James E., Gross, P., Bellon, Joseph G., \& Langton, Loup. (2013). Influence of Celebrity Endorsement of Advertisement on Students Purchase Intention. J Mass Communicat Journalism. 3(3). 1-7

Rodriguez, Karina P. (2008). Apparel Brand Endorsers and Their Effects on Purchase Intentions: A Study of Philippine Consumers. Philippine Management Review. 15. 83-99

Ruslim, Tommy Setiawan dan Richard Andrew. (2012). Pengaruh Brand image dan Product knowlage Terhadap Purchase Intention (Kasus: Kosmetik Merek "X"). Media Bisnis Universitas Tarumanegara, 4(1), hal:34-44.

Shiffman,.L.G \& Kanuk, L.L. (2006). Perilaku Konsumen. Jakarta: Indeks

Shimp, Terence A. (2014). Komunikasi Pemasaran Terpadu dalam Periklanan dan Promosi Edisi 8. Jakarta: Salemba empat

Stephanie, E., Rumambi, L. J., dan Sondang, Y. (2013). Analisa Pengaruh Rio Dewanto dan Donita Sebagai Celebrity Endorser Terhadap Niat Beli Produk Axe Anarchy Dengan Daya Tarik Iklan dan efek Iklan Sebagai Variabel Intervening. Jurnal Manajemen Pemasaran. 1(2) h: 1-9.

Sugiyono.(2016). Metode Penelitian Manajemen.Bandung:Alfabeta

Terlutter, R., Diehl, S., \& Mueller, B. (2006). The GLOBE study-applicability of a new typology of cultural dimensions for cross-cultural marketing and advertising research. International Advertising and ..., 420-438.

Till, Brian D. \& Shimp, Terence A. (1998). Endorsers in Advertising: The Case of Negative Celebrity Information. Journal of Advertising. 27(1). 67-82

Top Brand Award. Kategori Perlengkapan Pribadi. http://www.topbrandaward.com/top-brand-surveyy/surveyyresult/top brand for teens index 2017Diakses 3 Maret 2018

Yang, Dong-Jenn, Lo, Jyue-Yo, \& Wang, Sheng.(2012). Transfer Effects: Exploring The Relationship Between Celebrity And Brand. The International Journal of Organizational Innovation, 4(4), 86-108 
Wahyuni, N.L.G., dan Suparna, G. 2014. Pengaruh Citra Merek dan Product Knowledge Terhadap Niat Membeli Produk Tas Tiruan di Kota Denpasar. EJurnal Manajemen Universitas Udayana, 3(4), hal. 1022-1034.

Wang, Ya-Hui., Cing-Fen Tsai.(2014). The Relationship Between Brand image and Purchase intention: Evidence From Award Winning Mutual Funds. The International Journal Business and Finance Research, 8(2), pp:27-40

$\mathrm{Wu}$, Chao-Sen. (2015). A Study on Consumers Attitude Towards Brand Image, Athletes Endorsement and Purchase Intention. The International Journal of Organizational Innovation . 8(2). 233-253

Wuryandari, N.E.R. (2014). Pengaruh Promotion Mix dan Perceived Price terhadap Visit Intention seta Implikasinya terhadap Willingness to Recommendation (Kajian pada Museum-Museum di Kota Bandung). Jurnal Mix 4 (1), hal.28-41. 